\title{
IMPLIKASI KEBIJAKAN AMERIKA SERIKAT DALAM PENERAPAN SISTEM DEMOKRASI DI MYANMAR PASCA PERANG DINGIN ${ }^{1}$
}

\author{
(Implications of U.S. Policy in Implementing Democracy Systems in Myanmar Post-Cold War)
}

\author{
Achmad Zulfikar, Diah Sulung Syafitri dan Muhammad Abdul Aziz Putra Andistan \\ Jurusan Ilmu Hubungan Internasional \\ Universitas Muhammadiyah Yogyakarta \\ Corresponding author: apa@kabarfikar.com
}

\begin{abstract}
Summary
Freedom for the community is an important point behind the presence of democratic values in the midst of the nation. Based on the past experience, the founding father of the American nation has learned that people restrictions by the government are not allowed, so the democratic values are really anti-coercion. The presence of democratic values in the absence of political participation in a country seems to be an oasis for the people of the country. The US view that makes democracy a means of creating peace as the German philosopher Immanuel Kant thinks that in a republic (a state of democratic law), where the policies of each state are determined according to the will of the citizens, and not the will of a dictator. In this discussion the author focuses on one of the countries in Southeast Asia are still unstable in the application of democracy, namely Myanmar. In the dynamics of US and Myanmar relations, the US exit from Myanmar due to the authoritarian military regime led Ne Win rejected all forms of US aid in 1963. But in 1990, the fresh air of democracy blew again when a new political force emerged namely the National League for Democracy (NLD) Aung San Suu Kyi. Encouraged by US desires to democratize Myanmar, the United States fully supports the NLD's struggle for US policy on democracy in Myanmar. Furthermore, the US policy of imposing economic sanctions on Myanmar in 1997 based on congressional decision is also implemented in order to suppress the military government of Myanmar in order to accelerate the transition to democracy. The two policies then led to internal turmoil in Myanmar which eventually urged the military government to immediately implement the democratic system. Based on our review there are seven implications that come from internal and external Myanmar. The US policy in the application of democratic system is considered successful, because the two US policies have an impact on democratic transition in Myanmar.
\end{abstract}

Keywords: U.S Policy, Democratic System, Myanmar

\section{Ringkasan}

Kebebasan bagi masyarakat merupakan poin penting yang melatarbelakangi kehadiran nilai-nilai Demokrasi di tengah-tengah bangsa Amerika. Berdasarkan pengalaman kelam di masa lalu, bapak pendiri bangsa Amerika telah belajar bahwa pengekangan terhadap masyarakat oleh pemerintah tidak boleh dilakukan, sehingga nilai-nilai Demokrasi ini benar-benar anti pemaksaan. Kehadiran nilai-nilai Demokrasi di saat keringnya partisipasi politik di suatu negara seakan menjadi oase bagi rakyat di negara tersebut. Pandangan AS yang menjadikan demokrasi sebagai sarana menciptakan perdamaian sebagaimana pemikiran filsuf Jerman Immanuel Kant yang menyatakan bahwa dalam sebuah republik (negara hukum demokratis), dimana kebijakan politik setiap negara ditentukan menurut kehendak warga negara, dan bukan kehendak seorang diktator. Dalam pembahasan ini penulis memfokuskan pada salah satu negara di kawasan Asia Tenggara yang masih labil dalam penerapan demokrasi, yakni

1 Makalah telah dikompetisikan dalam International Relations Paper Competition yang diselenggarakan oleh Himpunan Mahasiswa Hubungan Internasional (HIMAHI) Universitas Pembangunan Nasional 'Veteran' Yogyakarta. Dipresentasikan dihadapan Dewan Juri pada 12 Juni 2013. 
Myanmar. Dalam dinamika hubungan AS dan Myanmar, keluarnya AS dari Myanmar dikarenakan rezim militer otoriter pimpinan Ne Win menolak segala bentuk bantuan AS tahun 1963. Namun tahun 1990, angin segar demokrasi kembali berhembus ketika suatu kekuatan politik baru muncul yakni National League for Democracy (NLD) pimpinan Aung San Suu Kyi. Didorong oleh keinginan AS mendemokrasikan Myanmar, maka AS mendukung penuh perjuangan NLD yang menjadi kebijakan AS dalam penerapan demokrasi di Myanmar. Selanjutnya kebijakan AS menerapkan sanksi ekonomi atas Myanmar tahun 1997 berdasarkan keputusan kongres juga dijalankan dalam rangka menekan pemerintahan militer Myanmar agar mempercepat transisi menuju demokrasi. Dua kebijakan tersebut kemudian menimbulkan gejolak internal di Myanmar yang akhirnya mendesak pemerintahan militer untuk segera menerapkan sistem demokrasi. Berdasarkan hasil penelaahan kami terdapat tujuh implikasi yang bersumber dari internal maupun eksternal Myanmar. Adapun kebijakan AS dalam penerapan sistem demokrasi dinilai sukses, karena dua kebijakan AS memberikan dampak terhadap transisi demokrasi di Myanmar.

Kata Kunci: Kebijakan Amerika Serikat, Sistem Demokrasi, Myanmar

\section{PENDAHULUAN}

\section{A. Latar Belakang}

Amerika Serikat seringkali disebut sebagai bapaknya Demokrasi. Hal ini tidak dapat dipungkiri karena negara ini pertama kali memperkenalkan istilah ini, kemudian menjalaninya hingga AS merasa sistem demokrasi ini berhasil di terapkan, maka dimulailah penyebaran benih-benih Demokrasi di berbagai dunia hingga saat ini.

Apabila kita tarik hubungan antara Demokrasi dan kebebasan, tentunya akan terlihat kaitan yang sangat erat. Asal usul berdirinya AS tidak terlepas dari keinginan untuk membebaskan diri dari pemerintahan represif Inggris abad ke-17. Orang-orang yang merasa tertekan ini kemudian melakukan pengembaraan melalui lautan atlantik.

Menurut Cipto, sebagian besar pendatang terdiri dari tukang kayu, petani, pedagang, ahli mesin, pelaut dan berbagai keahlian lainnya. Namun tidak semua pendatang tiba dengan selamat di benua baru. Dari pendatang inilah yang menjadi cikal-bakal bangsa Amerika yang sesungguhnya. ${ }^{2}$

Di tengah situasi politik represif yang melanda masyarakat Inggris abad ke-17 bersamaan dengan itu muncul para pemikir yang buah pikirannya kemudian menjadi dasar ideologi bangsa Amerika. Pemikiran-pemikiran mereka sama sekali tidak disukai oleh pemerintah kerajaan Inggris. Akan tetapi, secara perlahan-lahan pemikiran tersebut menyeberang ke benua baru dan kemudian tumbuh berkembang bersama masyarakat baru.

Salah satu pemikir besar Eropa yang sangat berpengaruh terhadap pemikiran politik Amerika adalah John Locke (1623-1704). Pakar filsafat politik Inggris ini dikenal memiliki pemikiran-pemikiran besar dan dianggap paling berpengaruh terhadap para bapak pendiri Amerika. Dari pemikiran John Locke ini banyak diperoleh benih-benih demokrasi yang kemudian dikembangkan secara luas dan mendalam oleh para pemikir Amerika.

Menurut Dewey dalam Cipto, Demokrasi memiliki dasar yang sangat sederhana, yakni adanya kebutuhan bagi setiap individu yang telah dewasa untuk ikut serta dalam membentuk nilai-nilai yang mengatur kehidupan bersama mereka. ${ }^{3}$ Demokrasi diyakini oleh bangsa Amerika sebagai prinsip dasar pembangunan watak bangsa. Hanya lewat partisipasi

\footnotetext{
${ }^{2}$ Bambang Cipto. Politik dan Pemerintahan Amerika. Yogyakarta: Lingkaran Buku, 2007. h. 2.

${ }^{3}$ Ibid., h. 3
} 
politik secara penuh dari setiap individu maka sebuah bangsa dapat mengembangkan diri sepenuhnya.

Lebih jauh, bahkan bangsa Amerika meyakini bahwa keagungan manusia hanya mungkin terwujud jika masyarakat memberi kesempatan sebesar-besarnya kepada setiap individu untuk ikutserta dalam pembentukan nilai-nilai yang mengatur kehidupan masyarakat tersebut. Dalam konteks ini, Amerika meyakini betul bahwa diktator mustahil diterima eksistensinya sebagai kenyataan hidup.

Sengaja kami paparkan hal tersebut di atas untuk memperlihatkan awal mula bangsa Amerika ini berdiri, hingga mereka menyepakati hadirnya nilai-nilai Demokrasi di tengahtengah mereka dalam rangka untuk memberikan kebebasan bagi masyarakatnya. Selanjutnya, perlu kita ketahui bahwa bapak pendiri bangsa Amerika telah belajar bahwa pengekangan terhadap masyarakat oleh pemerintah tidak boleh dilakukan, sehingga nilai-nilai Demokrasi ini benar-benar anti pemaksaan, jika kita berangkat dari sejarah Amerika itu sendiri.

Pada penjelasan di atas telah ditekankan bahwa "Amerika meyakini betul bahwa diktator mustahil diterima esksitensinya sebagai kenyataan hidup". Pernyataan ini kemudian akan ditelaah lebih lanjut dengan fakta-fakta yang terjadi terkait dengan implikasi kebijakan Amerika Serikat dalam penerapan sistem demokrasi di Myanmar.

Seperti yang kita ketahui bahwa dekade terakhir ini hubungan AS dan Myanmar seringkali diwarnai ketegangan dikarenakan kebijakan AS yang sangat gigih menginginkan penerapan demokrasi sebenar-benarnya di Myanmar. Ketegangan tersebut disebabkan sikap AS yang mengeluarkan kebijakan berupa sanksi ekonomi kepada negara junta militer ini.

Apabila kita tarik lebih jauh hubungan antara AS dan Myanmar pada masa perang dingin. Maka dapat kita temukan hubungan yang mulai renggang sebab $\mathrm{Ne}$ Win yang merupakan panglima militer beraliran sosialis berhasil melakukan kudeta pada tahun 1958 dan 1962 terhadap pemerintahan sipil Myanmar. Hal ini menyebabkan pada tahun 1963, seluruh bantuan AS ditolak oleh Myanmar dibawah kekuasaan Ne Win.

Sejak berada dalam kekuasaan Ne Win, Myanmar menolak segala bentuk bantuan dari negara kapitalis. Hal ini berlangsung hingga terjadinya Pemilu tahun 1990 yang memenangkan National League for Democracy (NLD) yang dipimpin Aung San Suu Kyi. AS kembali mengambil peran untuk mendukung aktivitas NLD dalam memperjuangkan demokrasi di Myanmar. Di waktu bersamaan, Uni Soviet yang merupakan seteru AS dalam perang dingin mengalami keruntuhan. Sehingga Amerika Serikat selaku pemenang perang menjadikan ideologinya beserta sistem yang dinamakan Demokrasi sebagai sistem universal yang disebarkan ke sleuruh dunia.

Sistem demokrasi ini kemudian diklaim sebagai salah satu cara untuk mendamaikan dunia. Peperangan yang terjadi dalam beberapa dekade terakhir ini tentunya menimbulkan banyak kerusakan dan kerugian pada pihak yang berperang maupun tidak. Maka dari itu, kehadiran sistem demokrasi ini sebagai cara yang ampuh untuk melanggengkan perdamaian.

\section{B. Rumusan Masalah}

Bagaimana implikasi kebijakan Amerika Serikat dalam penerapan sistem demokrasi di Myanmar pasca perang dingin?

\section{PEMBAHASAN}




\section{A. Pandangan Amerika Serikat terhadap Demokrasi Perdamaian}

Sebelum melangkah lebih jauh dalam mengkaji implikasi penerapan sistem demokrasi di Myanmar. Maka perlu diketahui bagaimana Amerika Serikat memandang demokrasi sebagai sarana untuk menciptakan perdamaian. Poin yang paling penting dalam kaitannya dengan Myanmar yakni kehadiran sistem demokrasi yang dibawa oleh AS diharapkan membawa angin segar bagi penyelesaian konflik yang telah terjadi sejak junta militer berkuasa. Berdasarkan penjelasan tersebut, maka sistem demokrasi dapat diartikan sebagai pembawa perdamaian.

Teori yang membentuk ide tentang pentingnya demokrasi dalam mewujudkan perdamaian dunia berasal dari pemikiran filsuf Jerman Immanuel Kant. Karyanya Zum Ewigen Frieden: Ein Philosophischer Entwurf (1795), menerangkan keterkaitan antara sistem politik republik dengan perdamaian abadi. "Republik" yang disebut oleh Kant adalah "demokrasi" yang kita kenal saat ini.

Menurut Kant, dalam sebuah republik (negara hukum demokratis), dimana kebijakan politik setiap negara ditentukan menurut kehendak warga negara, dan bukan kehendak seorang diktator, hubungan antar-negara akan terbiasa dengan harmoni dan bukannya konflik.

Penjelasan Kant sederhana, "Apabila persetujuan warga negara dibutuhkan dalam memutuskan pernyataan perang (dan ini menjadi ketentuan dalam konstitusi demokrasi), tidak ada yang lebih alamiah daripada kenyataan bahwa warga negara akan sangat berhatihati untuk memutuskannya, karena hal itu dapat menjerumuskan mereka ke dalam malapetaka. Malapetaka tersebut meliputi: keharusan untuk bertempur, mengorbankan sumber daya yang dimiliki, memperbaiki kehancuran akibat perang, dan menyebabkan negara terbebani dengan besarnya utang untuk membiayai perang".

Dalam literatur ilmu hubungan internasional, ide Kant ini dikenal sebagai teori perdamaian demokrasi, yakni teori yang menjelaskan bahwa negara demokrasi tidak akan saling berperang satu sama lain, atau dalam kalimat Michael W. Doyle di Jurnal Philosophy \& Public Affairs (1983), "even though liberal states have become involved in numerous wars with nonliberal states, constitutionally secure liberal states have yet engage in war with one another"4.

Dengan bersandar pada warisan pemikiran filosofi Kant tentang perdamaian demokrasi, para pemimpin eksekutif di AS menilai bahwa negara-negara non demokrasi yang hingga saat ini masih dipimpin oleh seorang diktator akan mengancam negara lainnya yang sudah demokrasi. Sehingga peluasan sistem ini akan berdampak pada perwujudan perdamaian dunia. Berdasarkan teori ini, Barack Obama saat pelantikannya sebagai Presiden AS tahun 2008 menyatakan, "harapan terbaik bagi terwujudnya perdamaian dunia adalah dengan melakukan ekspansi kebebasan/demokrasi ke seluruh seluruh dunia. Mereka juga percaya, bahwa insting agresif pemerintahan diktator militer dapat menyebabkan perang."5

Berdasarkan penjelasan di atas, maka dapat disimpulkan bahwa ambisi Amerika Serikat dalam melakukan perluasan sistem demokrasi ke berbagai negara non demokrasi di

\footnotetext{
${ }^{4}$ Michael W. Doyle, "Imanuel Kant Perpetual Peace: A Philosophical Sketch" [https://www.mtholyoke.edu/acad/intrel/kant/kant1.htm] diakses 10 Oktober 2012.

${ }_{5}^{5}$ Richard D. Heffner with Alexander Heffner, A Documentary History of The United States: Expanded and Updated Eighth Edition, USA: A Signet Book, 2009. hh. 663-665.
} 
dunia dilandaskan pada pada keyakinan bahwa sistem demokrasi ini merupakan sarana untuk menciptakan perdamaian yang diinginkan. Di samping itu, keberadaan pemimpin yang diktator sangat berpotensi untuk menyebabkan perang.

Jika melihat dari perspektif ini, maka posisi Amerika Serikat terhadap Myanmar sangat didasari kekhawatiran bahwa negara ini membuat geopolitik di kawasan Asia, khususnya Asia Tenggara menjadi tidak stabil. Maka berbagai cara dilakukan oleh Amerika Serikat untuk menjadikan negara ini menganut sistem demokrasi guna melindungi negaranegara yang telah menjadi sekutunya.

\section{B. Dinamika Hubungan Amerika Serikat-Myanmar}

Selanjutnya, pada bagian ini penulis akan menelaah dinamika hubungan Amerika Serikat-Myanmar. John H. Badgley (Peneliti National Bureau of Asian Research) mengevaluasi hubungan antara AS dan Myanmar dalam empat periode besar.

Periode pertama, warisan sejarah- sejak dimulainya Perang Dunia II, AS mendekati Myanmar untuk alasan strategis. Ribuan penerbang Amerika meninggal saat penerbangan Hump, pencarian jasad mereka berlanjut dengan kerjasama militer Myanmar. Ratusan tentara AS diterjunkan ke utara Burma, di mana mereka memperoleh pelabuhan yang aman dan bergabung dengan gerilyawan Kachin melawan Jepang. Tindakan legendaris ini meninggalkan kesan yang tak terhapuskan pada kedua negara Amerika dan Myanmar, dan tetap menjadi benang penting dalam hubungan sejarah mereka.

Periode kedua, keterlibatan dalam perang dingin- sampai tahun 1962 pemerintah AS dan yayasan swasta mengirimkan misi ke Myanmar pada setiap bidang, dan menjadi sumber utama bantuan asing dan masukan bagi ekonomi. Perdagangan dan investasi asing juga diperluas, namun bantuan ini dicurigai oleh politisi sosialis dan Jenderal Ne Win yang tidak mempercayai pengusaha kapitalis. Kudeta Ne Win pada tahun 1958 dan 1962 menjadikan ideologi sosialisme serta mengontrol militer.

Akhirnya, Myanmar menolak bantuan lebih lanjut Amerika pada tahun 1963, dan menolak tawaran AS untuk memberikan bantuan ke Rangoon pada akhir tahun 1960 ketika Revolusi Kebudayaan Cina mengekspansi Myanmar dan kembali memicu pemberontakan komunis. Ne Win memandang tawaran bantuan sebagai hal yang bertentangan dengan kepentingan keamanan Myanmar dan landasan kebijakan luar negeri Burma. Pihak Pertama Kongres dari Partai Sosialis Burma Program (BSPP) menegaskan kembali baris ini pada tahun 1971. Tetapi pada Kongres Partai Kedua pada tahun 1973, sekelompok perwira militer aktif dari perintah lapangan terpilih untuk Komite Sentral Partai, dan mereka membawa rasa kebutuhan untuk keluar dari isolasi Myanmar.

Di kelompok yang lebih terbuka adalah perwira senior yang hati-hati menerima pendekatan AS pada tahun 1974 untuk membahas program kontra-narkotika. Hal ini menyebabkan proyek pengadaan selusin helikopter dan empat pesawat sayap tetap untuk operasi terhadap pedagang narkotika di negara bagian Shan.

Periode ketiga, liberalisasi- dalam konteks ini merupakan upaya perluasan hubungan internasional dan kemakmuran, upaya bertahun-tahun ini pada akhirnya mengantarkan Myanmar pada penyelenggaraan Pemilu tahun 1990. Sebagai hasil dari liberalisasi ini, partisipasi masyarakat sipil dalam pemerintahan lokal dan regional diperluas. 
Sejak tahun 1988, Amerika Serikat telah memfokuskan kepentingannya kepada National League for Democracy (NLD) dan pemimpinnya, Aung San Suu Kyi. Adapun AS mensubordinasi kepentingannya terhadap tindakan junta dengan menyesuaikan pada prioritas NLD-yaitu, untuk meminta kembali demokrasi, dan bertindak sebagai oposisi junta militer.

Periode keempat, sanksi vs keterlibatan kembali. Tiga kelompok swasta di Amerika Serikat terus mencari keterlibatan dengan Myanmar: perusahaan energi dengan kemitraan eksplorasi, organisasi non-pemerintah di bidang kemanusiaan berupaya untuk memperluas program bantuan kecil di Kachin dan Shan, dan ekspatriat Myanmar yang mempertahankan hubungan dekat dengan keluarga mereka dan menyaksikan dampak negatif sanksi terhadap orang-orang biasa. Namun, kedua administrasi Demokrat dan Republik sejak tahun 1988 telah mengundurkan diri dari keterlibatan, menunjukkan keengganan untuk mengatasi krisis kesehatan meningkat Myanmar, dengan pengecualian keprihatinan untuk HIV/AIDS, yang telah menyebar secara luas melalui populasi di Myanmar.

Sanksi AS terhadap perdagangan dan investasi pertama kali diterapkan pada tahun 1997, diperkuat Maret 2002 dengan resolusi kongres, dan meningkat untuk membatasi setiap perdagangan dalam dolar AS. Sekarang, bagaimanapun, konvergensi kepentingan strategis beberapa negara besar Asia di Myanmar menunjukkan saatnya untuk menguji kembali kepentingan AS di Myanmar. ${ }^{6}$

\section{Implikasi Kebijakan Amerika Serikat dalam Penerapan Sistem Demokrasi di Myanmar Pasca Perang Dingin}

Pada bagian sebelumnya penulis telah membahas hubungan Amerika SerikatMyanmar yang dievaluasi oleh John H. Badgley. Selanjutnya di bagian ini penulis ingin mengukur implikasi kebijakan Amerika Serikat yang telah disebutkan pada bagian sebelumnya bahwa pada masa pasca perang dingin Amerika Serikat mulai mengeluarkan kebijakan-kebijakan seperti: mendukung perjuangan National League for Democracy (NLD), hingga mengeluarkan sanksi terhadap perdagangan dan investasi Myanmar sejak 1997.

Menghadapi masa-masa sulit dengan tekanan dari berbagai pihak tentunya menuntut pemerintah Myanmar melakukan introspeksi terhadap hubungannya dengan Amerika Serikat yang menginginkan penerapan sistem demokrasi di Myanmar. Sebagaimana tujuan AS dalam perdamaian demokrasi yakni menerapkan sistem demokrasi sebagai sarana pembawa perdamaian bagi negara-negara di seluruh dunia. Beberapa implikasi telah mulai terlihat dari kebijakan AS dalam penerapan demokrasi di Myanmar sebagai berikut.

Pertama, dijinkannya National League for Democracy (NLD) ikut berkompetisi dalam pemilu. Dalam pemilu yang diselenggarakan pada 1 April 2012, NLD pimpinan Suu Kyi berhasil meraih kemenangan besar. NLD meraih 43 dari 45 kursi parlemen terbuka, dan 37 pada Majelis Rendah Dewan Perwakilan Rakyat. Suu Kyi sendirimemenangkan kursi DPR dengan konstituen di wilayah Kawhmu, Yangon. Ia dan anggota parlemen partainya dilantik pada 2 Mei2012.

\footnotetext{
${ }^{6}$ John. H. Badgley (ed). "Reconciling Burma/Myanmar" [http://mercury.ethz.ch/serviceengine/Files/ISN/106464/ipublicationdocument_singledocument/e3b3f2f7-11d44c48-9323-6b81e8e2e439/en/vol15no1.pdf], hh. 13-16.
} 
Kedua, dibebaskannya para tahanan politik. Jika dulu junta militer menangkap semua aktivis politik yang dinilai membahayakan kekuasaan, kini sebagian dari mereka telah dibebaskan.

Ketiga, dicabutnya sistem sensor terhadap pers. Hampir 50 tahun sejak kudeta militer, Agustus 1962, kebebasan pers Myanmar memang dipasung. Media dilarang keras menerbitkan tulisan yang dinilai junta mengancam ketertiban, keamanan, dan perdamaian. Tidak sedikit wartawan dipenjarakan tanpa proses peradilan karena tulisannya dinilai mengganggu ketertiban dan keamanan (Kompas, 19/9/2012). Namun kini pers di Myanmar tidak lagi dibatasi, wartawan dapat dengan bebas melakukan penulisan dan peliputan berita tanpa takut dikenai sensor dan sanksi penangkapan oleh pemerintah.

Keempat, jika dulu catatan hak asasi manusia dimasa junta militer begitu buruk, kini situasinya telah berubah. Sebagaimana yang pernah dikatakan oleh penasihat hukum Presiden Thein Sein, U Sit Aye beberapa waktu lalu, bahwa konstitusi dan pemerintahan baru telah menjamin promosi hak-hak asasi manusia dengan dibentuknya Komisi Hak Asasi Manusia.

Kelima, para buruh yang dimasa junta militer tidak memiliki kebebasan untuk menuntut kesejahteraan, saat ini justru diberikan kebebasan untuk mendirikan serikat pekerja dan kebebasan untuk melakukan unjuk rasa.

Keenam, apresiasi yang diberikan oleh ASEAN terhadap Myanmar. Para pemimpin ASEAN dalam Konferensi Tingkat Tinggi ASEAN ke-19 di Nusa Dua, Bali, pada November 2011, sepakat untuk menyerahkan ketua ASEAN 2014 kepada Myanmar. Hal itu diputuskan setelah mereka melihat momentum dan perubahan yang berarti di Myanmar karena telah menjadi negara yang demokratis dan menghargai hak-hak asasi manusia.

Ketujuh, apresiasi terhadap Myanmar yang diberikan oleh AS. Hal ini dapat di lihat dari kunjungan Menteri Luar Negeri AS Hillary Clinton ke Myanmar selama dua hari (34/12/2011). Kunjungan Clinton ini penting bagi Myanmar mengingat hubungan kedua negara yang tidak pernah membaik sejak tahun 1955. Meskipun belum ada tanda-tanda Menlu Clinton akan mencabut sanksi ekonomi terhadap Myanmar, namun ia tetap mengakui terdapatnya perubahan ke arah yang lebih baik dan demokratis di Myanmar. ${ }^{7}$

Hasil serupa ditunjukkan dalam GenevaPapers yang diterbitkan oleh Geneva Centre for Security Policy (GCSP). Dalam laporan bertajuk Virtuality Perception, and Reality in Myanmar's Democratic Reform yang ditulis oleh Victoria Christensen menyebutkan bahwa indikator transisi demokrasi di Myanmar dapat dilihat dari tiga hal. Pertama, transparansi politik dan sistem pemerintahan. Indikator ini terdiri atas kebebasan pers, pembebasan tahanan politik Aung San Suu Kyi, dan reformasi dalam sistem pemilu. Kedua, pembebasan tahanan politik. Ketiga, penghentian konflik etnis dan pelanggaran HAM. ${ }^{8}$

Berdasarkan pemaparan di atas terkait implikasi kebijakan AS terhadap penerapan demokrasi di Myanmar. Maka dapat disimpulkan bahwa kebijakan AS untuk mendukung perjuangan National League for Democracy (NLD), hingga mengeluarkan sanksi terhadap perdagangan dan investasi Myanmar sejak 1997 pada akhirnya memberikan dampak yang

\footnotetext{
${ }^{7}$ Asrudin. "Harmoni dalam Demokrasi Myanmar" [http://indonesian.irib.ir/artikel1//asset_publisher/7xTQ/content/harmoni-dalam-demokrasi-myanmar/pop_up] diakses 2 Juni 2013.

${ }^{8}$ Victoria Christensen, "Virtuality Perception, and Reality in Myanmar's Democratic Reform" [http://www.humansecuritygateway.com/documents/GCSP_VirtualityPerceptionandRealityinMyanmarsDemocr aticReform.pdf] diakses 2 Juni 2013.
} 
signifikan bagi transisi demokrasi di Myanmar. Walaupun masih ada beberapa hal yang hingga saat ini masih dalam proses seperti masih terjadinya konflik etnis di Myanmar.

\section{PENUTUP}

\section{A. Kesimpulan}

Amerika Serikat yang dikenal sebagai bapak Demokrasi menyadari betul hadirnya nilai-nilai Demokrasi di tengah-tengah mereka merupakan sarana untuk memberikan kebebasan bagi masyarakatnya. Dalam hal ini, bangsa Amerika meyakini bahwa keagungan manusia hanya mungkin terwujud jika masyarakat memberi kesempatan sebesar-besarnya kepada setiap individu untuk ikutserta dalam pembentukan nilai-nilai yang mengatur kehidupan masyarakat tersebut. Dalam konteks ini, Amerika meyakini betul bahwa diktator mustahil diterima eksistensinya sebagai kenyataan hidup.

Terjadinya berbagai macam penindasan oleh pemerintahan yang otoriter di beberapa negara mendorong AS untuk turut campur dalam rangka membebaskan rakyat negara tersebut. Myanmar merupakan salah satu contoh upaya AS dalam mendorong terwujudnya demokrasi di suatu negara melalui berbagai macam pendekatan pasca negara tersebut dikuasai oleh militer yang mendepak posisi AS di Myanmar tahun 1963.

Kegigihan AS dalam usahanya menerapkan sistem demokrasi di Myanmar, didasari keyakinan bahwa sistem demokrasi merupakan sarana untuk menciptakan perdamaian yang diinginkan. Di samping itu, keberadaan pemimpin yang diktator sangat berpotensi untuk menyebabkan perang.

Walaupun posisi AS di tahun 1963 didepak oleh pemerintahan Myanmar yang dikuasai junta militer. Namun kemenangan National League for Democracy (NLD) yang dipimpin Aung San Suu Kyi pada pemilu tahun 1990, memberikan peluang bagi AS untuk kembali mengambil peran dalam rangka mendorong diterapkannya sistem demokrasi di Myanmar.

Tahun 1997, berdasarkan keputusan Kongres AS juga menjatuhkan sanksi ekonomi kepada Myanmar untuk menekan pemerintahan junta militer agar segera menerapkan sistem demokrasi. Keputusan ini diikuti dukungan dari masyarakat internasional, dan kawasan Asia Tenggara agar Myanmar segera berbenah diri.

Upaya yang dilakukan AS dan dukungan masyarakat internasional ini pada akhirnya menuai hasil antara lain: diijinkannya NLD ikut berkompetisi pada Pemilu 2012 yang meraih kemenangan besar, dibebaskannya tahanan politik yang dulunya ditangkap oleh junta militer, dicabutnya sistem sensor terhadap pers, meningkatnya perhatian pemerintahan junta militer dalam promosi hak-hak asasi manusia, disetujuinya Myanmar sebagai Ketua ASEAN 2014, hingga kunjungan Menlu AS Hillary Clinton ke Myanmar pada Desember 2011.

Upaya AS dalam menjalankan demokrasi perdamaian di Myanmar merupakan salah satu contoh kesuksesan. Walaupun secara tidak langsung diterapkan di Myanmar, namun sedikit demi sedikit sistem demokrasi tersebut dapat diterima oleh pemerintah Myanmar melalui pengakuan terhadap hak-hak politik sipil, maupun pembenahan diri melalui tata aturan dalam pemerintahan. Sehingga kelak Myanmar akan benar-benar menjadi negara yang demokratis, sebagaimana yang diinginkan oleh AS. 


\section{BIBLIOGRAPHY}

Buku

Boller, Jr., Paul F. Presidential Campaign. New York: Oxford University Press, 1996.

Burchill, Scott, Andrew Linklater. Theories of International Relations. New York: ST.

Martin's Press Inc., 1996.

Cipto. Bambang. Politik dan Pemerintahan Amerika. Yogyakarta: Lingkaran Buku, 2007.

Heffner, Richard D. and Alexander Heffner. A Documentary History of The United States: Expanded and Updated Eighth Edition. USA: A Signet Book, 2009.

Miller, Lynn H. Agenda Politik Internasional. Yogyakarta, Pustaka Pelajar, 2006.

Mulyana (ed.) Demokrasi dalam Budaya Lokal. Yogyakarta: Tiara Wacana, 2005.

Pratt, Julius W. A History of United States Foreign Policy: Second Edition.USA: Prentice Hall, 1990.

Rachman, Muhammad Fadjroel. Demokrasi Tanpa Kaum Demokrat: Tentang Kebebasan, Demokrasi, dan Negara Kesejahteraan. Depok: Penerbit Koekoesan, 2007.

Shiddiq, Muhammad. Demokrasi Yang Terpenjarakan. Yogyakarta: Gemini Publishing, 2012.

Winarno, Budi. Isu-Isu Global Kontemporer. Yogyakarta: Center for Academic Publishing Service, 2011.

Zamroni. Pendidikan Demokrasi pada Masyarakat Multikultural. Yogyakarta: Galvin Kalam Utama, 2011.

Internet

Asrudin, "AS dan Perdamaian Demokrasi"

[http://suar.okezone.com/read/2011/04/19/58/447613/as-dan-perdamaian-demokrasi] diakses 2 Juni 2013.

Asrudin, "Harmoni dalam Demokrasi Myanmar" [http://indonesian.irib.ir/artikel1//asset_publisher/7xTQ/content/harmoni-dalam-demokrasi-myanmar/pop_up] diakses 2 Juni 2013.

Ido Oren, "The Subjectivity of the 'Democratic' Peace: Changing U.S. Perceptions of Imperial Germany" [http://www.mtholyoke.edu/acad/intrel/oren.htm] diakses 2 Juni 2013.

John. H. Badgley (ed), "Reconciling Burma/Myanmar"

[http://mercury.ethz.ch/serviceengine/Files/ISN/106464/ipublicationdocument_singledocume nt/e3b3f2f7-11d4-4c48-9323-6b81e8e2e439/en/vol15no1.pdf], hh. 13-16. 
Michael W. Doyle, "Imanuel Kant Perpetual Peace: A Philosophical Sketch"

[https://www.mtholyoke.edu/acad/intrel/kant/kant1.htm] diakses 2 Juni 2013.

Uni Sosial Demokrat, "Mengapa AS Keluarkan UU Khusus tentang Myanmar"

[http://www.unisosdem.org/article_detail.php?aid=2339\&coid=3\&caid=31\&gid=1] diakses 2 Juni 2013.

Victoria Christensen, "Virtuality Perception, and Reality in Myanmar's Democratic Reform" [http://www.humansecuritygateway.com/documents/GCSP_VirtualityPerceptionandRealityin MyanmarsDemocraticReform.pdf] diakses 2 Juni 2013. 